\title{
CODE OF PRACTICE FOR RADIOLOGICAL PROTECTION
}

A NEW Code of Practice concerned with protection arrangements against hazards arising from the use of ionizing radiation in medical work has now been published*. This Code replaces that published in 1957. Codes of practice of this sort are obviously difficult to produce and when produced are equally obviously a target for criticism.

The old Code of 1957 has long since needed modification. There have been very many developments in the field of radiation hazard control in the past seven years. We may have surmounted a peak of agitation about radiation hazards and be able to assess somewhat less dramatically where the hazards really lie. A code of some sort must, however, be available since there are very many people involved in radiation work who require guidance. It is gratifying that the Code contains clauses using the word 'must', indicating an essential requirement, and others containing 'should', indicating a desirable one. Some flexibility to meet local circumstances and opportunities is essential even though no one will agree that all the 'musts' and 'shoulds' are in the right place.

The new Code is a great step forward from the old one. It is intended to apply not only to the staff exposed to ionizing radiations in the National Health Service hospitals as did the old Code, but also to those exposed in all forms of medical and dental practice and allied research in hospitals. It has been closely matched with a Code published somewhat earlier by the Ministry of Labour to apply to research and teaching institutions. Family doctors and dentists using X-rays are asked to apply the provisions that are relevant to their work.

In the field of administrative arrangements the new Code sets out much more clearly than the old one a welldefined chain of responsibility. The duties of various committees and persons in this chain are specified. Perhaps the least satisfactory part of this arrangement is the lack of clarity in defining the duties of the supervisory medical officer. It is not clear whether the officer will be an expert on the clinical effects of radiation or one with responsibility for the normal health of those members of staff who are subject to hazard. * Department of Education and Science; Ministry of Health; Scottish Home and Health Department; Ministry of Health and Local Government for Northern Ireland. Code of Practice for the Protection of Persons against Ionising Radiations arising from Medical
London: H.M.S.O., 1964.) 12s. 6 d. net.
There is a very substantial improvement in the section of the Code dealing with the handling of unsealed radioactive materials. Particularly welcome are the sections on procedures in laboratories and wards and emergency action in the event of a spill. The sections on disposal of waste, discharge of patients during treatment with radioactive isotopes, and storage and movement of radioactive materials summarize the existing arrangements usefully.

The section dealing with hazards to patients is new. Here are incorporated the essential recommendations of the Adrian Committee on Radiological Hazards to Patients. It is possible that, together with a much more vigorous administrative approach to the problem of hazard control which the Code might stimulate, this inclusion of patient dose control might produce the most marked effects of all the new provisions. On the basis of the Code diagnostic radiologists should be stimulated to look again at their techniques, not only from the point of view of the staff but also from the point of view of the patient dose, and this could have quite an important effect on producing the improvements which the Adrian Report suggested were possible without sacrifice of diagnostic information.

Nevertheless, there are still some questions that radiological safety advisers, radiological protection officers, supervisory medical officers, boards of governors, hospital management committees and radiological safety committees will want to ask about hazard control in hospitals for which no answer is given in the Code. This is the price they pay for the flexibility which they appreciate. It is also a reflexion on the fact that at the level of risk involved in the overwhelming proportion of this work firm statements cannot always be made. The radiological protection advisers and the supervisory medical officers will need to keep in touch with authoritative discussions on their problems, so that they may exercise judgment to give a right balance between quite adequate safety and the valuable and necessary use of ionizing radiations in the medical field.

A Code for medical work is needed-and this looks like being a very important step between the first one in 1957 and the perfect one, still to be produced. It is produced by an authoritative panel, and the separate Handbook of Radiological Data, to contain technical information relative to the implementation of the Code, will, we hope, not be long delayed.

H. MrLLER

\section{DENSIFICATION OF PARTICULATE MATERIALS}

\footnotetext{
$\mathrm{T}$ HE Materials Science Club * held the first of its technical meetings at the Battersea College of Technology during February 26-27.

The general theme of the meeting was the densification of particulate materials, and this was covered in three half-day sessions. The first of these consisted of three papers, each followed by a short discussion period, and a visit at the end of the session to the laboratories of the Department of Metallurgy and Materials Technology.

Prof. J. D. Bernal (Birkbeck College) provided an elegant introduction to the meeting by covering the ground between the arrangement of atoms in a crystalline structure and the packing of solid particles of irregular shape. Many of the packing characteristics of these solids can be studied by using ball-bearings as models. The speaker showed how, by the use of a deformable 'box', a heap of ball-bearings could be gradually compacted * Nature, 204, 831 (1964).
}

through a range of packing densities until the closest possible random-packing was achieved. In this arrangement the minimum void content was 36 per cent as compared with 25 per cent in a regular close-packed crystal. The structure of such an arrangement could also be studied by pouring paint through the voids, and measuring the positions of the points of contact indicated by the dried paint as the successive layers of spheres were stripped away. Measurements showed that instead of the twelve points of contact encountered in crystals, the number was about nine in random close-packing. A study of the voids in this type of packing showed that there were five different shapes, based on tetrahedra, octahedra and three more complex polyhedra.

Even with spheres it was observed that structures based on a random close-packed arrangement were very stable, since any change in shape had to be accompanied by an expansion. With granular materials, however, particles 
of difforont sizes occurred, but it seemed that, provided the size differences were less than 10 por cent, these could bo tolerated in random eloso-packing. Where the differences were greater, the style of packing changod, and voids began to be filled. Where deposition occurred, it was also possible to fill tho voids by crystallization.

'J'hese methods of studying the packing of solids havo the limitation that they are not transparent and therefore restricted observation. Prof. Bernal mentioned that to overcome this disadvantage some work had boen done with transparent spheres in a clear liquid of the same refractive index.

In opening the discussion, Mr. L. Holliday (Shell Chomical Co., Ltd.) observed that it had boon reported that the structure of somo precious opals showed a very high degree of regularity. Prof. Bernal replied that the colour was in fact due to this regularity, depending not on the size of the particle but simply on the geometry. In considering particles of different shapes, Dr. J. P. Roborts (University of Leeds) askod if highor densities could be attained with flat plates as in some ceramics, and Dr. P. E. Evans (Manchester College of Science and Technology) wondered if work had been done on the packing of spheres with rods. Apparently none had, but with plates it was possible to get densities of up to 90 per cent or so. Here, though, a surface effect might have to be considered, as overy departure from the spherical resulted in an increase in surface aroa. This effect of shapo and surfaco would also apply to the different methods of depositing sand (vibrution, wind, water) in dunes, referred to by $\mathrm{Mr}$. Amirsuliemani (University of Birmingham).

Dr. K. Newman (Imperial Collogo of Science and Technology) asked what parameters should be considered in the study of the particles in concreto. Prof. Bornal said that the treatment required tho uso of statistical geometry, but as this was searcoly possible it was necessary to elimin. ate all complications and even then rely on a more or less einpirical approach. Prof. A. J. Konnedy (College of Aeronautics) observed that a solid containing very many dislocations compared with the numbor of atoms might approach a random close-packed structure. Dr. Clarke also asked if dislocations were related to the different shapes of void. Prof. Bernal replicd that structures with many dislocations had beon produced at the Building Research Association, but that even with many dislocations there was still a gap between theso and the structures referred to in his lecture. Mr. Holliday suggested that the gap could bo bridged with paracrystals, and Prof. Bornal admitted that this might be so, although these were not usually spherical.

The second speaker in this session was Mr. R. L. Samuol, of tho Battersea College of Technology, who gave a brief account of the resoarch boing carried out in the Departinent of Metallurgy and Materials Technology. Tho subjects include powder metallurgy, alloy constitution, transformation in alloys, diffusion and re-crystallization in metals, doformation and mechanical proportios of metals, surface treatment and protoction of motals. The work on powders was offectively concentrated under 4 main headings: (i) Properties, including morphology, sizo and strain. Ultrafine particlos woro also boing studied in the range $1 \mu-100 \AA$, and attention was being directed to the problems of accurate measurements in this region. Strain in coramics such as the alkali halides and carbides during milling was also under investigation. (ii) Densification and sintoring, including different methods of sintering. Both chemical and thermal mothods were being studied. (iii) Changes accompanying sintering. (iv) Means of strongthening products. An examplo is the dispersion of small particles in niekel alloys, and of iron in austenitic steels.

Prof. J. Kolbuszewski (Univorsity of Birmingham) spoke of the density of sand. Sund, with a particle size range of $20.06 \mathrm{~mm}$, lins between gravel and silts and clays.
In studying the behaviour of these materials we are interested in (i) their strength, (ii) consolidation, (iii) compaction. In the last-mentionod case, artificial means such as tamping, rolling, eto., are used. Although we are primarily interested in the state of the material in situ, it is necessury to prepare samples for exarnination in the laboratory. In clays sampling is relativoly easy, but with sands it is difficult, sinco the transfer of samples from the sampling tools to the laboratory is almost impossible. The state of sand is described in terms of density or porosity $N$. The values $N_{\max }$ and $N_{\min }$ have to bo measured in the laboratory, whereas $N_{\text {neld }}$ has to bo measured in the field and repeatod in tho laboratory. In sample prepara. tion, the volocity of pouring into the test vessel, as woll as the method of deposition, have an effect on the value of $N$, but it is relatively casy to find $N_{\max }$ either by deposition in water-to avoid support from the walls and to eliminate vertical channels-or by rapidly tilting tho vessol. To obtain $N_{\min }$, however, is difficult, since vibration is required, and if the intensity is too great crushing results. From this study it was noted that volume changes in granular materials occur as a result of one or more of the following: olastic deformation, plastic deformation, or crushing under load. 'The following generalizations can also be made: porosity decreases with increased intensity of vibrations and then decreases to a constant value. Porosity also decreases with timo during vibration to a minimum value, after which further vibration has no effect. Particle shapes and grading affect both the values of $N_{\mathrm{min}}$ and the required acesloration to produce this value, round sand requiring less. Both $N_{\max }$ and $N_{\min }$ are lower for round than for angular sands. Finally, from studios of all representative sands found in Britain, it appears that there is a definite relationship between the limiting porosities for a given sand, and the arithmotic mean of these differences is 9.5 per cent. In reply to questions, Prof. Kolbuszewski said that the different components of vibration had been separated during the study, and it had been found that a frequency range of $26-30 \mathrm{c} / \mathrm{s}$ was best. Workers on tho shear strongths of sands and soils had observed anisotropic behaviour.

Dr. D. Train (Cremer and Warner) opened the second session with a review paper on the agglomeration of solids by compaction. Initially, within a bed of powder ther is essentially only point contact between tho particles. When an external force is applied, however, atomic, molecular and electrostatic forces can have sufficient influence to produce a stable structure. Stress concontrations develop adjacent to the areas of contact and local deformation of the material follows. Depending on such factors as the rate of application, magnitude and duration of the stresses, as woll as tho nature of the material, this doformation can be cither elastic, plastic or destructive. In addition to this deformation, consolidation will also take place owing to particles sliding over one another, to an oxtent depending greatly on the frictional properties of the solids. In practice, it is also necessary to take into account the offects of the dic walls and punch faces, or the surfaces of the compacting rollers, depending on which method is used. A further problem is the contamination of the particles by oxide films, grense and lubricants. Finally, Dr. Train considered the use of isostatic pressing, whereby the use of a hydrostatic pressuro ensures even application on all surfaces, and climinates the effect of the dis wall.

Dr. K. A. Lammiman (Esso Research, Lta.) reported that ho had usod dyos to follow changes in donsity during and ufter compaction. Dr. N. C. Moore (Plessoy U.K., L.td.) observed that entrapment of gases in compacted solids could causo stresses. Dr. Train said that the spoods used in his own work made this unlikely, but that it could become a problom in production.

Mr. D. J. Shourman (Royal School of Mines) dealt with the doposition and cementation of limestone. Limestone, which accounts for 20-30 per eent of the Earth's sedimen- 
tary rocks, consists of $\mathrm{CaCO}_{3}$. At the Earth's surface the rocks are solids consisting of shell particles comented together with ealcite. But at considerable depths below the surface the rocks show quite a high degree of porosity. In one type of rock structure the shell particles are segments of sea-urchin shells. These segments are of caleite and contain a large number of channels. Cementation takes place by crystal overgrowth on the spaces between the channels. The first stage of growth is in the form of needles which gradually coalesce until the entire segment is surrounded by a single crystal of calcite; this crystal is then cemented to others by further deposition of calcite. There are two phases in the development: in the first, the calcite overgrowth next to the sea-urchin segment is of pure calcite, and in the second later phase there are often traces of $\mathrm{Fe}$ in the calcite cement, possibly due to the presence of contaminated water as the rocks near the Earth's surface.

In another type of limestone the shells are those of snails, and are made of a different form of $\mathrm{CaCO}_{3}$-aragonite. In rock samples which are relatively young-3 or $4 \times 10^{4}$ years old-the shells often appear to have dissolved leaving voids in the calcite cement. As the age of the rock increases small crystals of calcite form along the lining of the voids, which gradually fill up, until at the age of $2 \times 10^{8}$ years or so the entire rock is composed of calcite. Shells of aragonite which have been dissolved in the laboratory have been found to be surrounded by an extremely thin, tough, mucillaginous m mmbrane secreted by colonies of blue-green algae found on the shells. This envelope remains in the rock when the aragonite has gone into solution, and provides a mould in which are deposited the crystals of calcite. Dr. Evans asked why there appeared to be two sizes of crystal in the voids, and also in the cement surrounding the shells. Mr. Shearman said the reason was not known, although the presence of an oil film could cause this phenomenon. Certainly there was no gradual transition; the erystals were either large or small. Dr. D. B. Honeyborne (Building Research Station) referred to formations such as bathstones where some grains had hollow cores, and whero there were also small tunnels in the grain walls. $\mathrm{Mr}$. Shearman said that in this type of rock the grains were often surrounded by aragonite and the familiar envelope of mucillage. It was known that the algae could bore holes, and this might account for the small tunnels.

The last paper in this session was given by Dr. P. E. Halstead (Cement and Concrete Association), who claimed to represent the link between the last two speakers, and spoke about packing and compaction in cement bound materials. The mothod of compacting cement-bound materials is unique, and densification is brought about by a kind of sodimentation process which exploits the rather peculiar rheological properties of cement-water suspensions. Other methods can be used; in one, compaction is achieved by pumping into the voids in a mass of stones a matorial which will harden. In another, the water is removed from the concrete by vacuum filtration, and in a spocial case of this latter method a mixture of cement and asbestos is subjected to vacuum filtration on a gauze web, and the resulting compacted felt removed to harden. The strength of a cement paste is directly related to its intrinsic compaction, and this compaction in turn depends on the water : cement ratio of the paste, since excess unreacted water will ultimately evaporate and leave voids. If we can use other methods than gravity to achieve compaction, it should be possible to make concrete with quite novel properties, although it seems probable that any such treatment would only be convenient for making relatively small articles of simple shape.

Mr. Long asked if a change in volume occurred on hydration and whether any benefit could be derived from such a change. Mr. Halstead replied that there was in fact a considerable change in volume, which could help to increase compaction by filling up interstices. Prof.
Bernal remarked that the strength of the concrete was at the points of contact. Good concrete was rare as it depended on the almost complete hydration of the cement. It was interesting to note that in all the systems we had considered so far there was a trend towards lower entropy. This was shown by the replacement of small by larger crystals and so on. The process was slow, as was exemplified by the transformation of snow into ice over a period of 30-40 years, and, although it was possible to speed up the change, there would inevitably be a loss of perfection.

Prof. J. White (University of Sheffield) delivered an evening lecture on the study of refractory materials, and the final session began with a paper on pressure sintering by Mr. J. G. Campbell (Morganite Carbon, Ltd.). Pressure sintering provides an economical method of forming, heat treating and sizing bodies produced from powdered materials by a single operation. The process increases the rate of densification and high densities may be achieved in shorter times and at lower temperatures than by cold pressing and sintering. Closer control of temperature-dependent phenomena, such as grain growth and phase transformation, may be obtained.

Pressure sintering would seem to be a simple process in that all that is required is a mould set containing a charge of particulate material which may be heated and pressure applied. In practice, however, each step becomes complex and is controlled by conditions which are critical. The stages in this process are as follows: (1) Occluded gases must be removed by a light, controlled pressure. This usually accounts for a contraction ratio of $2 \cdot 5$ or 3 to 1 . (2) Mechanical compaction occurs, due to particle rearrangement as a result of fragmentation, accompanied by some plastic deformation. According to conditions and materials, some diffusion may occur. These processes are likely to continue to relatively high densities. (3) These are essentially diffusion-controlled stages due to improved particle-to-particle contact, particle rearrangement, increased defect or vacancy concentration, the results of plastic flow and fragmentation. This contribution of diffusion increases with intergranular contact and the decrease in the level of pore-size distribution. (4) Bulk diffusion predominates until the remaining pores are discrete, then grain boundary diffusion is likely to control the rate of final pore closure.

In this flow process the material is assumed to behave as a simple Bingham solid, that is when no plastic flow occurs until a critical yield stress is reached. Above this point it is considered that the material behaves as a Newtonian liquid with a very high viscosity. Before the process can be practised it is necessary to examine the availability of materials with suitable high-temperature properties and behaviour for the construction of mould sets. Graphite, under non-oxidizing conditions, is the highest temperature/stable elemental solid known, and with the most recently developed refinements is a suitable material. Mr. Campbell discussed the practical aspects of the design of punches, and concluded with some theoretical considerations of the relationships between end-point density, and temperature and pressure. Dr. Roberts asked whether, in view of the apparent care needed in the sequence of operation, this process could be used commercially at an economical rate. The speaker replied that a rotary multi-mould system had been tried out which showed promise.

Prof. J. M. Alexander (Imperial College of Science and Technology), Dr. D. S. Davies (I.C.I., Ltd., Petrochemical and Polymer Laboratory), Dr. Morantz and the session chairman, Dr. C. Edeleanu (I.C.I. Agricultural Division), engaged in a lively discussion on the morits of using an Arrhenius plot to show the activation energy of shear. Mr. Holliday inferred from the speakers' remarks that the philosopher's stone of two continuous phases had been achieved and was disappointed when this was denied. In a discussion on surface effects, Dr. Davies wondered 
whether surface changes would reveal a discontinuity in the plot of $\log p$ against $1 / T$.

Mr. C. R. Shakespeare (B.S.A. Group Research Centre) gave a talk covering several aspects of powder metallurgy. In ordor to improve the strength of components it is necessary to increase the density, and this can be done either by increasing the working temperature or pressure, or better still by using a mothod of increasing particle compaction. Mr. Shakespearo described experiments with atomized $\mathrm{Cu}$ particlos, where, using vibrating compaction, densities equivalent to those obtained in a standard press at 10 tons/in. ${ }^{2}$ wore achioved at pressures of only 0.5 ton $/$ in. $^{2}$ with solection of the most favourable amplitudes and frequencies.

The effect of particle size differences was to increase the density up to a poak value, after which it fell again. Sections of pressings showed that variation did not appear to cause segregation of different sizes. In the isostatic method of compaction, the particles are contained in a flexible metal envelope, which is compressed by the action of hot oil, or by an inert gas at $1,000^{\circ} \mathrm{C}$ and 10,000 lb./in ${ }^{2}$. There were convection current problems in using gas, and more work on heat transfer was needed.

Finally, Mr. Shakespeare described the production of strip by extrusion of metal powders. The powder was first pro-compacted by isostatic pressing, thon placed in a can and extruded. Some motals like nickol could be prepared more choaply in powder form than in billets, but with powders there was still the problem of increased surface oxidation. Benefits in improved strength occurred with powder extrusion, as small and uniform grain sizes were achioved in the final product.

Mr. Long wondered if the startling reductions in pressure resulting from vibration compaction were in fact real and suggested that strain gauges should be used to check this. Argon is used for isostatic pressing in Britain, as opposed to helium, which is used in the United States. In answer to a question by Mr. King (I.C.I. Agricultural Division), Mr. Morgan (B.S.A. (Group Research Centre) said that $N_{\mathrm{min}}$ was reached after $10 \mathrm{sec}$ compared with the $6 \mathrm{~min}$ quoted earlier for concreto. Drs. Duvies and Lammiman wished to ensure that techniques like these which showed promise should be widely publicized. Prof. Alexander asked if cold oxtrusion could be used to reduce oxide contamination. It seemed that good results had in fact been obtained by this method.
Mr. A. (X. Thomas (Plessey U.K., Ltd.) spoke on the fabrication of transparent bodies by hot pressing. There was a need in the fields of rockct, missile and satellite technology for transparent materials which wore transparent to infra-red radiation and capable of withstanding high temperatures. Materials with suitable high-termperature characteristics are the polycrystalline ceramics, but these are often opaque. Their opacity is caused by failure to achieve theoretical density, by the presonco of grain boundary cracks resulting from abnormal grain growth, and also by the presence of a second phase or precipitate often due to the presence of additives intendod to promote sintering. All these phenomena give rise to a loss of transparency by causing internal reflexions, and the impurities may give rise to absorption bands at undesirable points in the spectrum. Free sulphur, for example, produees transmission in the $0 \cdot 4-2 \cdot 0 \mu$ range in zine sulphide. The development of 'Lucalox' and other transparent aluminas has shown that by careful attention to purity, particle size and sintering conditions, theoretically dense porefree ceramics can be produced by conventional fabrication techniques. The use of hot-pressing tochniques has made it easier to produce fine-grained articles at comparatively low temperatures. The spcaker concluded with a description of the mechanical properties and optical charaeteristics of ceramic 'windows' made by the hot-pressing technique.

Dr. Morantz asked if the decrcase in transparency was due to the presence of water, but it seemed that grain size was the principal cause, although Dr. Clarke mentioned that in magnesium oxide opacity was due to the presence of impurities rather than to large grains. Dr. Evans believed that this was duo to the different distribution of impurities at grain boundaries compared with other sites.

In the final discussion, several speakers referred to a difference in attitude botween engineers and fundamental scientists, and Dr. Evans in particular maintained that engineers always refer to welding of a mass and do not think of the atoms involved in sintering. Mr. Shakespeare said that the gap between theory and practice was larger than was often realized, since theory only dealt with spherical particles, but these were only rarely encountered in practice. Prof. Alexander wondered if the theoretical troatment could be extended to include cubes, which would be a significant approach towards angular particles. W. A. HOLMES-WALKer

\title{
COMPLEMENTARY STEREOSPECIFIC INTERACTION BETWEEN ISOTACTIC AND SYNDIOTACTIC POLYMER MOLECULES
}

\author{
By A. M. LIQUORI, G. ANZUINO, V. M. COIRO, M. D'ALAGNI, P. DE SANTIS and M. SAVINO \\ Istituto Chimico, Università di Napoli, Italy, and Centro Nazionale di Chimica delle Macromolecole (CNR) Sez. III
}

$\mathrm{E}$ VER since the discovery of storeospecific polymerization of $\alpha$-olefins by Natta ${ }^{1}$ and his school it has beon clear that stereo-controlled addition of non-symmetrical vinyl monomers could lead to two distinct typos of stereoregular polymer molecules.

In the isotactio polymer the configuration of repeating monomer units is the same, whereas in the syndiotestic molecule it is alternating. Equivalence of monomer units leading to ordered macromolecular conformations packed in woll-defined crystal lattices requires either the ono or the other type of stereo-regularity.

Fox et al. ${ }^{2}$ have reported the stereo-regular polymerization of mothylmethacrylato using metallorganic catalysts and photochemical initiation. Mainly on the basis of the $X$-ray diffraction photographs of the various samples obtained under difforent conditions, tho nuthors concluded that three different crystallizable types of polymethylmeth- acrylate (PMMA) could be obtained. In addition to tho expected isotactic and syndiotactic polymers, which were later clearly identified, those authors thought there existed a crystallizable 'stereo-block' polymer characterizod by relatively short syndiotactic and isotactic linear sequences within the samo molecule.

Many papers were published afterwards along theso lines, and the hypothosis of an ordered stereo-block polymer became widely accepted.

The conditions for obtaining isotactic, syndiotactic and stereo-block fractions of high 'steric purity' became better defined $\mathrm{d}^{4-8}$ and various physical criteria, mainly based on infra-red and nuclear magnetic resonance spectra, woro devolopod to charactorizo thom ${ }^{7-9}$. We were reluctant to believe that a stereo-block polymor could crystallize, and thought that its existence was difficult to reconcile with the similarity exhibited botwoon many physieal properties 